Revista Verde de Agroecologia e Desenvolvimento Sustentável

http://www.gvaa.com.br/revista/index.php/RVADS

ARTIGO CIENTÍFICO

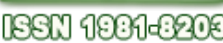

DOI: http://dx.doi.org/10.18378/rvads.v10i2.2965

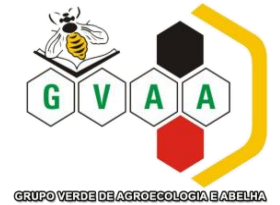

\title{
Biometria e morfologia da semente e plântula de oiticica
}

\section{Biometry and morphology of seed and seedling of oiticica}

Fábio Oliveira Diniz ${ }^{1 *}$, Sebastião Medeiros Filho ${ }^{2}$, Antônio Marcos Esmeraldo Bezerra ${ }^{2}$, Francisco José Carvalho Moreira ${ }^{3}$

Resumo: A carência de trabalhos sobre plantas nativas da Caatinga nordestina é perceptível, sobretudo, no que se refere aos estudos de suas sementes. Dentre as referidas espécies, destaca-se por seus múltiplos usos, a oiticica (Licania rigida Benth). Objetivou-se com este trabalho determinar e descrever a biometria e morfologia da semente e plântula de oiticica. O trabalho foi conduzido no Laboratório de Análises de Sementes do Departamento de Fitotecnia/UFC. Foram realizadas, nas sementes, medições individuais de comprimento, largura e espessura e a determinação morfológica de suas partes internas e externas, além da caracterização da plântula com suas respectivas estruturas. A semente de oiticica é eurispérmica, apresenta comprimento de 3,1 a 5,0 cm, largura de 1,3 a 1,7 cm e espessura de 1,2 a 1,7 cm. O embrião é grande de formato linear, com cotilédones carnosos de cor branca amarelada, dobrados e apresentam nervuras e o eixo hipocótilo-radícula curto. Germinação inicia-se aos 15 dias, sendo hipógea criptocotiledonar. A plântula possui nas faces dos primórdios foliares, uma camada esbranquiçada com aspecto cotonoso.

Palavras-chaves: Licania rigida Benth, germinação, Caatinga.

Abstract: Lack of works in native plants of caatinga northeastern is obvious, especially, relating to study of seeds. Among these species, stands out for its multiple uses, the oiticica (Licania rigida Benth). The objective of present experiment was to determinate the biometry and morphology the seed and seedling of Licania rigida. The essay was conducted at the Laboratory of Analysis of Seeds of the Phytotechny Department/UFC. Used were what measurement referent this length, width end thickness as well as detailed description internal end external of seed. Results showed that the seeds are euryspermycs, has length 3.1 to $5.0 \mathrm{~cm}$, width 1.3 to $1.7 \mathrm{~cm}$ and thickness 1.2 to $1.7 \mathrm{~cm}$. The embryo is large linear format, with fleshy cotyled ons yellowed, folded white and have short ribs and the hypocotyl-radicle axis. Germination starts after 15 days, hypogeal cryptocotylar. The seedling has the faces of the leaf primordia, a whitish layer cotonoso aspect.

Key words: Licania rigida Benth, germination, Caatinga.

\footnotetext{
*Autor para correspondência

Recebido para publicação em 30/09/2014; aprovado em 29/04/2015

${ }^{1}$ Eng. Agr. M. Sc., Prof. Instituto Federal de Educação, Ciência e Tecnologia do Piauí - IFPI, 64860-000 - Uruçuí, PI. dinizagro@ gmail.com

${ }^{2}$ Eng. Agr. D. Sc., Prof. Associado IV do Departamento de Fitotecnia/CCA/UFC, 60356-000 - Fortaleza, CE, filho@ufc.br

${ }^{2}$ Eng. Agr. D. Sc., Prof. Adjunto do Departamento de Fitotecnia/CCA/UFC, 60356-000 - Fortaleza, CE, esmeraldo@ufc.br

${ }^{3}$ Eng. Agr. M. Sc., Prof. Instituto Federal de Educação, Ciência e Tecnologia do Ceará - IFCE, 62040-730 - Sobral, CE, franzecm@ gmail.com
} 


\section{INTRODUÇÃO}

A Licania rigida Benth. (oiticica, Chrysobalanaceae) é uma planta nativa do Nordeste brasileiro, ocorrendo principalmente nos estados do Rio Grande do Norte, Paraíba, Piauí e Ceará (DINIZ et al., 2008). As formas de utilização desta planta vão desde o aproveitamento de sua refrigélida sombra em meio à aridez da Caatinga, à medicina popular, mas com destaque especial para extração do óleo de suas sementes, muito requerido pela indústria de óleos e vernizes nas décadas de 1930 a 1960. Recentemente, vem sendo apontada como matéria-prima potencial para produção de biodiesel (OLIVEIRA et al., 2012; QUEIROGA et al., 2013).

A espécie é propagada sexuadamente. No entanto, apresenta algumas dificuldades, como germinação irregular e perda da viabilidade relativamente rápida, além de grande variação no tamanho de suas sementes e da quantidade de óleo nelas contido. Para Duque (2004), pode-se até questionar, se trata realmente de uma só espécie, dada a variabilidade de tamanho, teor de óleo e produção de sementes.

A junção dos caracteres da semente e da plântula pode fornecer inúmeros indícios para a identificação das espécies a campo e em amostras de sementes. Com tais conhecimentos pode-se melhor propagar as espécies e contribuir para regeneração dos ecossistemas florestais. Os caracteres internos e externos das sementes contribuem sobremaneira para a identificação confiável, uma vez que são poucos influenciados por fatores ambientais (FERREIRA \& BORGHETTI, 2004).

Os estudos morfológicos de sementes e plântulas com intuito de se conhecer suas estruturas, além de fornecer informações sobre germinação, variabilidade, armazenamento e métodos de semeadura, auxiliam na identificação das espécies, principalmente, quando há redução da população natural, como no caso da Caatinga nordestina. A importância da vegetação nativa da Região Nordeste do Brasil é indiscutível, não só em função da diversidade de espécies, mas principalmente pela multiplicidade de usos (MAIA, 2004). Por apresentar exploração em caráter extrativista, pode levar a uma série de problemas, como a possibilidade de desaparecimento de algumas espécies florestais.

Embora trabalhos relacionados à biometria e morfologia de sementes de espécies nativas ou de ocorrência na Caatinga tenham sido conduzidos, Erythrina velutina Willd (SILVA et al., 2008), Erytrina variegata (Matheus; Lopes, 2007), Carthamus tinctorius L. (ABUD et al., 2010), Dalbergia nigra (BRAZ et al., 2009), Copernicia prunifera (REIS et al., 2010), Amburana cearensis (Fr. All.) A. C. Smith. (LOUREIRO et al., 2013), Dalbergia cearensis Ducke (NOGUEIRA et al., 2010), ainda são relativamente escassas informações biométricas e morfológicas de sementes e plântulas de grande número de espécies.

Diante do exposto, buscando acrescentar as informações a respeito das espécies do bioma Caatinga, o presente estudo teve como objetivo determinar e descrever a biometria e morfologia da semente e plântula de Licania rigida Benth.

\section{MATERIAL E MÉTODOS}

As sementes foram coletadas de diversos exemplares localizados no Campus do Pici da Universidade Federal do
Ceará, em Fortaleza-CE (latitude $3^{\circ} 44 \mathrm{~S}$, longitude $38^{\circ} 33 \mathrm{~W}$ e altitude 19,5m) e, logo em seguida, levadas ao Laboratório de Análise de Sementes do Departamento de Fitotecnia/UFC, onde foram obtidos o teor de água e peso de mil sementes (BRASIL, 2009), bem como, as determinações e descrições biométricas e morfológicas.

Foram amostradas 100 (cem) sementes para as medições individuais de comprimento, largura e espessura, utilizandose um paquímetro digital da marca Starret 727, com precisão de $0,01 \mathrm{~mm}$. De posse dos dados, calculou-se as médias aritméticas, desvio padrão, coeficiente de variação e intervalo de variação dos valores obtidos, com o auxílio do programa computacional Excel $\mathrm{XP}^{\circledR}$. A avaliação da morfologia foi realizada em sementes não embebidas, usando-se lupa de mesa com braço flexível, sendo os descritores analisados divididos em internos e externos (FERREIRA \& BORGHETTI, 2004).

Para as avaliações da morfologia da germinação e da plântula, quatro repetições de 15 (quinze) sementes foram semeadas em caixas plásticas de volume aproximado de 2 litros, contendo areia lavada e esterilizada e mantidas em casa de vegetação com $50 \%$ de sombreamento. As observações ocorreram diariamente a partir do $10^{\circ}$ até o $30^{\circ}$ dia, tendo como aspectos analisados a protrusão da radícula, raiz primária e secundária, colo, hipocótilo, cotilédones, epicótilo e protófilos.

\section{RESULTADOS E DISCUSSÃO}

As sementes de Licania rigida apresentaram dimensões que variam de 3,1 a 5,0 cm de comprimento, de 1,3 a 1,7 cm de largura e de 1,2 a 1,7 cm de espessura (Tabela 1), peso médio de mil sementes de $3,46 \mathrm{Kg}$ e teor de água de $34,6 \%$.

Com relação aos resultados biométricos, Bayma (1957), cita a ocorrência de sementes compridas, com comprimento de até $7,5 \mathrm{~cm}$ e largura de $2,2 \mathrm{~cm}$ e sementes arredondadas, com apenas 2,5 cm de comprimento por $1,0 \mathrm{~cm}$ de largura. Quanto ao peso das sementes, os resultados são bem similares, embora esse autor não tenha se reportado ao teor de água nelas contida. Menciona que para formar um quilo, são necessárias 218 a 294 unidades, semelhante ao observado no presente estudo (289 sementes).

As sementes apresentam como caracteres externos, tegumento de coloração verde, esmaecendo-se à medida que a semente perde água. Quando desprovida do tegumento e com teor de água elevado, observa-se coloração branca amarelada, tornando-se escuras quando secas. $\mathrm{O}$ escurecimento evidenciado nas sementes pode ser o resultado da oxidação do óleo em contato com o ar. A semente é do tipo eurispérmica, possui forma oblonga com a superfície sulcada, hilo saliente e micrópila inconspícuos (Figura 1).

Quanto às características internas, a semente é exalbuminosa, possui tecido de reserva oleaginoso de consistência firme e com coloração branca amarelada. O embrião apresenta tamanho grande e formato linear, sendo os cotilédones carnosos (crassos), dobrados com nervuras e o eixo hipocótilo-radícula curto (Figura $1 \mathrm{G}$ e $1 \mathrm{~J}$ ). A dobra dos cotilédones proporciona a existência de um espaço aerífero (Figura 1I). Tudo indica, que este espaço confere à semente a capacidade de boiar, de modo que seja facilmente transportada pelas enxurradas, visto que, não por acaso, o 
habitat preferido pela espécie são os aluviões que margeiam os rios e riachos (DINIZ NETO et al., 2014).

Tabela 1 - Média, desvio padrão, coeficiente de variação e intervalo de variação referentes ao comprimento, largura e espessura de sementes de Licania rígida Benth.

\begin{tabular}{lllcl}
\hline Determinações & \multirow{2}{*}{ Média } & $\begin{array}{l}\text { Desvio } \\
\text { Padrão }\end{array}$ & $\begin{array}{c}\text { Coef. de Variação } \\
(\%)\end{array}$ & $\begin{array}{c}\text { Intervalo } \\
\text { de Variação }\end{array}$ \\
\hline Comprimento $(\mathrm{cm})$ & 3,8 & 0,30 & 9,0 & $3,1-5,0$ \\
Largura $(\mathrm{cm})$ & 1,5 & 0,09 & 6,4 & $1,3-1,7$ \\
Espessura $(\mathrm{cm})$ & 1,4 & 0,12 & 8,4 & $1,2-1,7$ \\
\hline
\end{tabular}

Figura 1. Aspectos morfológicos da semente de oiticica (Licania rigida Benth.) A - vista frontal da semente; B - vista da região lateral da semente; $\mathrm{C}$ - vista da região ventral da semente; $\mathrm{D}$ - vista da região dorsal da semente; $\mathrm{E}$ - vista frontal da semente; F - vista do corte anterior; $\mathrm{G}$ - vista região posterior com detalhe dos cotilédones; $\mathrm{H}$ - corte longitudinal da semente; I - vista dorsal com detalhe do espaço aerífero; J - ventral com detalhe do eixo hipocótilo-radícula.

B.
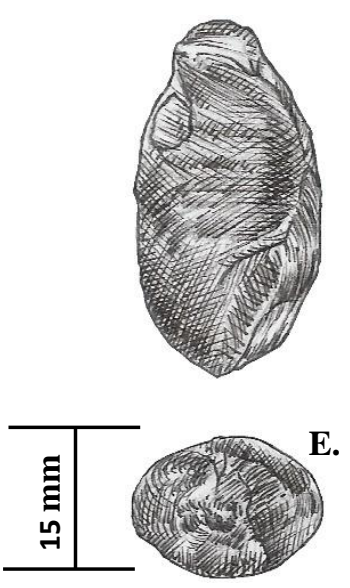

H.

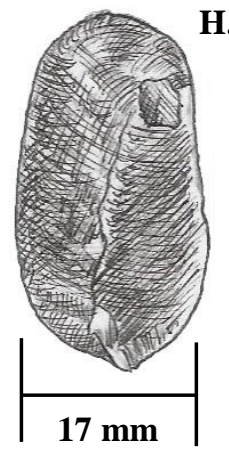

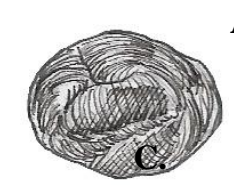
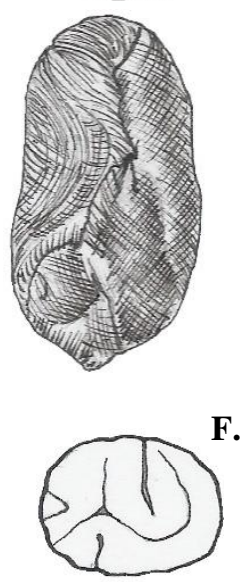

I.

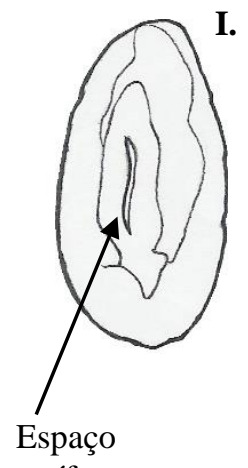

aerífero

F.
A.
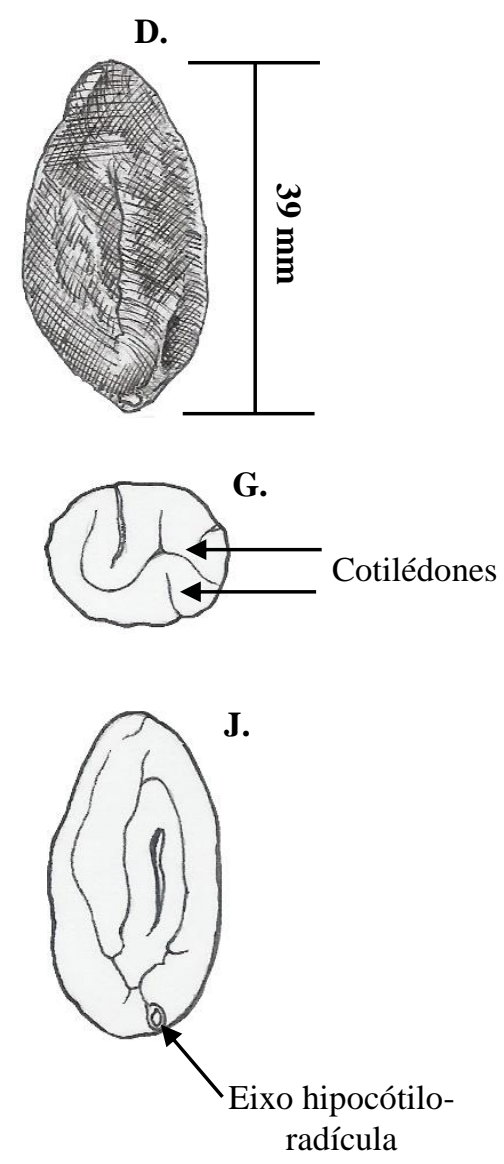

O processo germinativo das sementes de oiticica iniciase aos 15 dias, considerando-se apenas a protrusão radicular, sendo a germinação hipógea criptocotiledonar (Figura 2), confirmando o tipo de germinação descrito por Prance (2007), para o gênero Licania.

Após o intumescimento da semente observa-se que a emissão da raiz primária, de coloração branca, próximo a região do hilo (Figura 2A). Inicialmente ocorre um expressivo crescimento dessa raiz axial, a qual possui uma coifa pontiaguda, seguindo-se o surgimento de várias raízes secundárias, de mesma coloração da raiz principal, curtas e finas, coincidindo, com a emergência do epicótilo (Figura 2D). O hipocótilo tem a mesma espessura da raiz primária, é curto e apresenta coloração esbranquiçada.

Monteiro et al. (2012) estudando a morfologia da germinação e da plântula de oitizeiro (Licania tomentosa (Benth.) Fritsch) constataram que a germinação também foi marcada pela protrusão da raiz primária, de coloração branca e cilíndrica e, posteriormente, ocorreu o desenvolvimento de raízes secundárias e o desenvolvimento reduzido do hipocótilo. 
Figura 2. Aspectos morfológicos da germinação da semente e desenvolvimento de plântula de oiticica (Licania rigida Benth.). A - início da protrusão da radícula; B - alongamento da raiz principal; C - emergência do epicótilo; D - surgimento de raízes secundárias; E - crescimento do epicótilo, hipocótilo, raiz primária e secundárias; F - presença de catáfilos e eófilos; G plântula formada. rp - raiz primária; rs - raiz secundaria; hp - hipocótilo; co - coleto; ep - epicótilo; ca - catáfilos; eo eófilos; mt - metáfilos.

A.

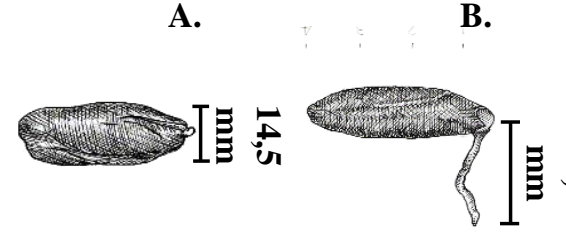

me

me

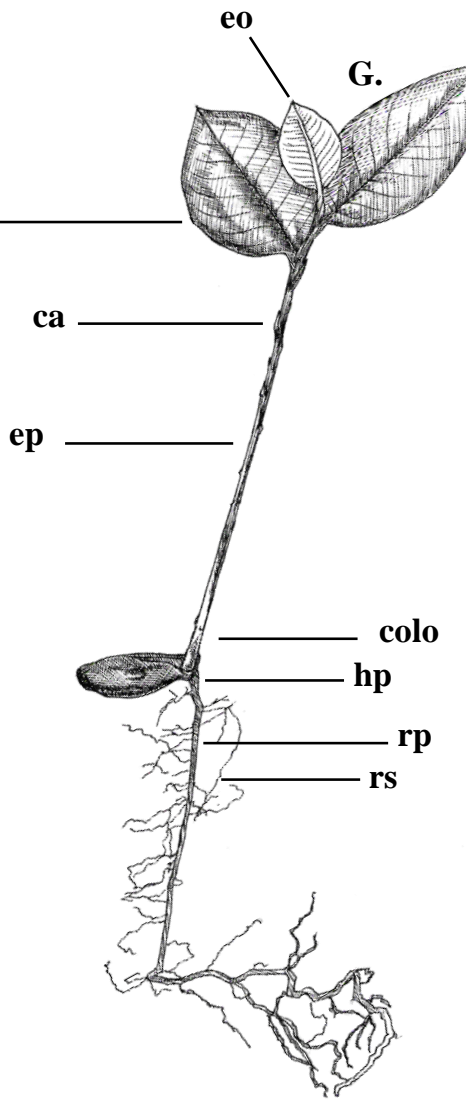

C.

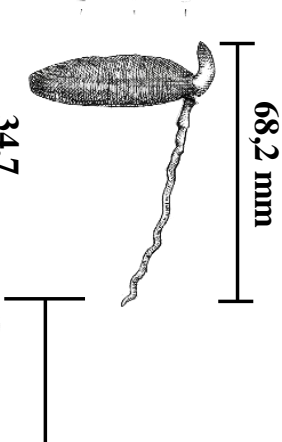

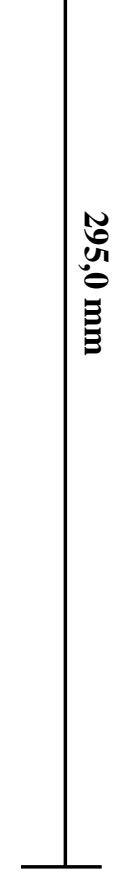

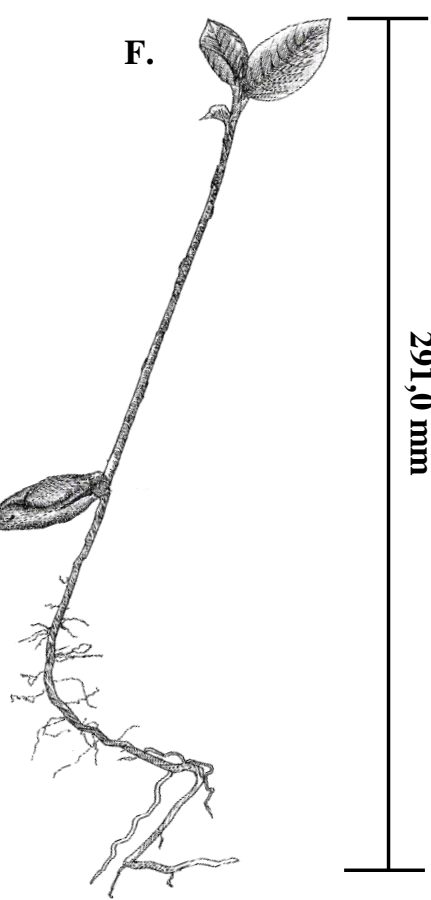

D.

E.

O epicótilo é cilíndrico e à medida que vai se alongando, surgem de forma alternada os catáfilos, seguidos pelos eófilos e metáfilos, ambos de coloração verde claro, consistência tenra, peciolados e com nervação peninérvea (Figura 2G). Neste estádio, todos os primórdios foliares e as folhas recém maduras apresentam nas duas faces uma camada esbranquiçada, com aspecto cotonoso. Monteiro et al. (2012), também evidenciaram em plântulas de oiti, folhas lanosas ou tomentosas, com tricomas simples e intensamente enrolados, dando um aspecto de lã nas superfícies adaxial e abaxial.

Supõe-se tratar-se de um mecanismo de proteção contra a excessiva transpiração provocada pelo clima árido do ambiente em que esta espécie se ocorre. Com o desenvolvimento da plântula, 30 dias após a germinação, a camada de cera protetora na face adaxial vai sendo perdida lentamente, uma vez que as folhas vão tornando-se coriáceas, mas tal proteção permanece na sua face abaxial. De acordo com Prance (2007), as folhas da Licania são oblongo-elípticas a oblongo-lanceoladas, abaxialmente glabra, quando

totalmente expandidas e, às vezes, quando são jovens, têm indumento lanoso-pubescente.

\section{CONCLUSÕES}

A semente de oiticica é eurispérmica, apresenta comprimento de 3,1 a $5,0 \mathrm{~cm}$, largura de 1,3 a $1,7 \mathrm{~cm}$ e espessura de 1,2 a $1,7 \mathrm{~cm}$.

O embrião é grande de formato linear, com cotilédones carnosos de cor branca amarelada, dobrados e apresentam nervuras e o eixo hipocótilo-radícula curto. A germinação inicia-se aos 15 dias, sendo hipógea criptocotiledonar.

A plântula possui nas duas faces dos primórdios foliares, uma camada esbranquiçada com aspecto cotonoso, que se perde à medida que as folhas amadurecem, cerca de 30 dias após a germinação. 


\section{REFERÊNCIAS BIBLIOGRÁFICAS}

ABUD, H.F.; GONÇALVES, N.R.; REIS, R.G.E.; GALLÃO, M.I.; INNECCO, R. Morfologia de sementes e plântulas de cártamos. Revista Ciência Agronômica, v.41, n.2, p.259-265, 2010.

BAYMA, C. Oiticica. Rio de Janeiro: Serviço de Informação Agrícola do Ministério da Agricultura, 1957. 140p.

BRASIL. Ministério da Agricultura, Pecuária e Abastecimento. Regras para análise de sementes. Ministério da Agricultura, Pecuária e Abastecimento. Secretaria de Defesa Agropecuária, Brasília, DF: MAPA/ACS, 2009. 395p.

BRAZ, M.S.S.; SOUZA, V.C.; ANDRADE, L.A.; BRUNO, R.L.A.; OLIVEIRA, L.S.B.; SILVA, J.M. Caracterização morfológica de frutos, sementes e plântulas de jacarandá-da- bahia (Dalbergia nigra (Vell.) Fr. All.ex. Benth) Leguminosae-Papilonoideae. Revista Brasileira de Ciências Agrárias, v.4, n.1, p.6771, 2009.

DINIZ, F.O.; MOREIRA, F.J.C.; SILVA, F.D.B.; MEDEIROS FILHO, S. Influência da luz e temperatura na germinação de sementes de oiticica (Licania rigida Benth). Revista Ciência Agronômica, vol.39, n.3, p.476480, 2008

DINIZ NETO, M.A.; SILVA, I.F.; CAVALCANTE, L.F.; DINIZ, B.L.M.T.; SILVA, J.C.A.; SILVA, E.C. Mudas de oiticica irrigadas com águas salinas no solo com biofertilizante bovino e potássio. Revista Brasileira de Engenharia Agrícola e Ambiental, v.18, n.1, p.10-18, 2014.

DUQUE, J.G. O nordeste e as lavouras xerófilas. 4ed. Fortaleza: Banco do Nordeste do Brasil, 2004. 330p.

FERREIRA, A.G.; BORGHETTI, F. Germinação: do básico ao aplicado. Porto Alegre: Artmed, 2004. 323p.

LOUREIRO, M.B.; TELES, C.A.S.; VIRGENS, I.O.; ARAÚJO, B.R.N.; FERNANDEZ, L.G.; CASTRO, R.D. Aspectos morfoanatômicos e fisiológicos de sementes e plântulas de Amburana cearensis (Fr. All.) A.C. Smith (Leguminosae - Papilionoideae). Revista Árvore, v.37, n.4, p.679-689. 2013.

MAIA, G. N. Caatinga: árvores e arbustos e suas utilidades. São Paulo: D \& Z, 2004. 413p.
MATHEUS, M. T.; LOPES, J.C. Morfologia de frutos, sementes e plântulas e germinação de sementes de Erythrina variegata L. Revista Brasileira de Sementes, v.29, n.3, p.8-15, 2007.

MONTEIRO, K.L.; OLIVEIRA, C.; SILVA, B.M.S.; MORO, F. V.; CARVALHO, D.A. Caracterização morfológica de frutos, de sementes e do desenvolvimento pósseminal de Licania tomentosa (Benth.) Fritsch. Ciência Rural, Santa Maria, v.42, n.1, p.90-97, 2012.

NOGUEIRA, F.C.B.; MEDEIROS FILHO, S.; GALLÃO, M.I. Caracterização da germinação e morfologia de frutos, sementes e plântulas de Dalbergia cearensis Ducke (pau-violeta) - Fabaceae. Acta Botânica Brasilica., v.24, n.4, p. 978-985, 2010.

OLIVEIRA, F.A.G.; PINTO, V.L.; SOUZA, L.; DINIZ, J.C.; SANTOS, A.G.D.; VIANNA, F.A. Síntese, caracterização e avaliação de biodiesel de óleo de oiticica (Licania rigida Benth) e isolalamento do éster metílico do ácido licânico. Química: ciência, tecnologia e sociedade, v.1, n.1, p.31-41, 2012.

PRANCE, G.T. Flora da reserva Ducke: Chrysobalanaceae. Rodriguésia, v.58, n.3, p.493-531, 2007.

QUEIROGA, V.P.; FREIRE, R.M.M.; MARINHO, D.R.F.; ALMEIDA, F.A.C.; MELO, B.A. Composição química e mineral de amêndoas de oiticica em três tempos de armazenamento. Revista Verde de Agroecologia e Desenvolvimento Sustentável, v.8, n.2, p.173-177, 2013.

REIS, R.G.E.; BEZERRA, A.M.E.; GONÇALVES, N.R.; PEREIRA, M.S.; FREITAS, J.B.S. Biometria e efeito da temperatura e tamanho das sementes na protrusão do pecíolo cotiledonar de carnaúba. Revista Ciência Agronômica, v.41, n.1, p.81-86, 2010.

SILVA, K.B.; ALVES, E.U.; BRUNO, R.L.A.; MATOS, V.P.; GONÇALVES, E.P. Morfologia de frutos, sementes, plântulas e plantas de Erythrina velutina willd., Leguminoseae - Papilionideae. Revista Brasileira de Sementes, v.30, n.3, p.104-114, 2008. 